\title{
Multiple Sclerosis and Diabetes Mellitus: Further Evidence of a Relationship
}

\author{
SHARON A. WARREN AND K.G. WARREN
}

SUMMARY: One hundred multiple sclerosis (MS) patients were compared to healthy controls to determine the prevalence of diabetes mellitus in their families. Significantly, more MS patients than controls were diabetic or reported at least one first degree relative (parent, sibling, child) with diabetes. The relationship between $M S$ and diabetes persisted when second degree relatives (grandparents, aunts and uncles) were taken into consideration.

RÉSUMÉ: Nous avons comparé l'incidence de diabète sucré dans les familles chez 100 patients atteints de sclérose en plaques (SEP) et 100 témoins normaux. Plus de patients SEP que de contrôles étaient euxmêmes diabétiques ou possédaient un proche parent (parents, fratrie, enfants) diabétique. Cette relation significative persistent dans l'étude des parents au $2 e$ degré (grands-parents, oncles et tantes).
A greater percentage of $M S$ patients with another $M S$ relative were diabetic or reported a first degree relative with diabetes mellitus than MS patients without an $M S$ relative. However the difference was not statistically significant. Nor was there a significant difference when percentages reporting either a first or a second degree relative with diabetes were compared.

Encore plus de patients SEP rapportaient du diabète familial s'il $y$ avait un autre cas de SEP dans leurs familles. Cependant cette dernière différence n'était pas significative. Il n'y avait pas de différences significatives des proportions de parents au premier ou second degré lorsque l'incidence de diabète familial fut étudié.
From the Department of Health Services, Ad ministration and Community Medicine and the MS Research Clinic, Division of Neurology, Department of Medicine, University of Alberta, Edmonton, Alberta.

Requests for Reprints to: Dr. Sharon Warren, As sistant Professor, Department of Health Services, Administration and Community Medicine, 13-103 Clinical Sciences Bldg., The University of Alberta, Edmonton, Alberta T6G 2 G3.
Several attempts have been made to determine whether any other illness is associated with multiple sclerosis (MS) in both patients and their families. Enrenteil et al (1952), McAlpine and Compston (1952), and Frovig et al (1967) have suggested that a greater percentage of MS patients than controls or their family members, are subject to allergies. Watkins and Espir (1969) suggest that more MS patients than controls may have migraine headaches prior to onset age. Sibley et al (1975) have suggested that families who are high risk for MS may be at increased risk for cancer. Documentation of other illnesses in MS patients and their families may provide clues to the pathogenesis of MS, and to the role of genetic factors.

Recently we reported on a study comparing 100 MS patients to 100 hospital patients (with other neurological and rheumatological problems) for a variety of coexisting illnesses, and other illnesses among their family members (Warren and Warren, 1981). That study found no relationship between MS and allergy, migraine or cancer. However, more MS patients than controls were either diabetic themselves or reported at least one blood relative with diabetes. MS patients who reported another relative with MS were also more likely to report a family history of diabetes mellitus than those who had no other relative with multiple sclerosis. Since relationships of this nature had not been reported previously, we attempted to confirm them in another series using healthy subjects as controls rather than hospital patients.

\section{METHODS}

Study Participants

The multiple sclerosis patients in this study were the first 100 who had their diagnoses confirmed at the University of Alberta MS Clinic following com- 
mencement of the study on January 1 , 1981. The majority (76\%) had developed their initial symptoms between the ages of 20 and $39 ; 13 \%$ developed symptoms prior to age 20 and $11 \%$ after age 39 . Females outnumbered males by a ratio of $2.8: 1$. All but one of the patients were Caucasian, and the majority (99\%) had spent most of their lives prior to age 15 in a high risk MS zone. Sixty-eight per cent of the patients were ambulatory. Thus the sample resembled the general distribution of MS patients (Acheson, 1975).

Controls were obtained from several sources and were matched to the MS patients on the basis of age, sex, race and zone of residence prior to age 15 . The MS patients were first asked to recommend a control from among their non-blood relatives, friends and associates. When this supply was exhausted, a woman's service club was approached. Members who volunteered to be controls were called in the order in which they had signed their names to a list circulated at their regular club meeting, and were matched to a female patient. Male controls were obtained from two other groups. Finally the staffs of the Department of Health Services Administration and Community Medicine, and of the Division of Neurology, were asked to recommend friends, co-workers and relatives who matched the remaining MS patients.

\section{Data Collection}

The MS patients and controls were interviewed by two trained interviewers who alternated between cases and controls. It was not possible to keep the interviewers blind, but the importance of questioning both groups with equal emphasis was stressed. Each participant was asked if he/she had ever been diagnosed as having diabetes, at what age, and what treatment regimen they were following. They were also asked whether any blood relatives had ever been diagnosed as having diabetes, and to give the specific relationship, age at diagnosis and treatment regimen. The total number of first and second degree relatives at risk was determined (i.e. all aunts, uncles, siblings and children, in addition to grandparents and parents). Participants were also asked if they had any blood relatives with MS, and to name the specific relationship.

\section{RESULTS}

\section{Comparison of Diabetes Rates in the}

Families of MS Patients and Controls

Eight of the MS patients and six of the controls were diabetic. There was no remarkable difference between the MS patients and controls in terms of the percentages of their first degree relatives (parents, siblings, children) and second degree relatives (grandparrents, aunts/uncles) who were diabetic. As a group, the MS patients reported a total of 30 first degree relatives and 44 second degree relatives with diabetes.
The patient groups' total number of first and second degree relatives at risk was 1996 , so that $3.7 \%(\mathrm{~N}=74)$ were diabetic. The control group reported 17 first degree relatives and 29 second degree relatives with diabetes. Their total number of family members at risk was 1851 , so that $2.5 \%(\mathrm{~N}=46)$ were diabetic.

There was a significant difference between the percentages of MS patients (31\%) and controls (13\%) who were either diabetic themselves or reported at least one first degree relative with diabetes (Table I). The relationship between MS and diabetes persisted when second degree relatives were also

\section{TABLE I}

Proportion of Cases and Controls Who Were Diabetic, or Reported at Least One First Degree Relative With Diabetes Mellitus

\begin{tabular}{lcccc}
\multicolumn{4}{c}{ First Degree Relative With Diabetes Mellitus } \\
& $\%$ & \multicolumn{2}{c}{ Controls } \\
& & $\mathbf{N}$ & $\%$ & $\mathbf{N}$ \\
Diabetic, or reported at & & & & \\
least one diabetic first & $31.0 \%$ & 31 & $13.0 \%$ & 13 \\
degree relative & $43.0 \%$ & 43 & $60.0 \%$ & 60 \\
Reported no diabetes & $26.0 \%$ & $26^{1}$ & $27.0 \%$ & $27^{2}$ \\
Missing, excluded & $100.0 \%$ & 100 & $100.0 \%$ & 100
\end{tabular}

$$
\mathrm{x}^{2}=10.5,1 \mathrm{df}, \mathrm{P}<.01
$$

${ }^{1}$ Eighteen cases who had a diabetic grandparent or aunt/uncle only, seven cases who reported only some other relative neither first nor second degree (e.g. cousin, niece/nephew), one adopted case.

${ }^{2}$ Seventeen controls who had a diabetic grandparent or aunt/uncle only, nine who reported only some other diabetic relative, one adopted control.

\section{TABLE II}

Proportion of Cases and Controls Who Were Diabetic, or Reported at Least One First or Second Degree Relative with Diabetes Mellitus

\begin{tabular}{lrcrc} 
& \multicolumn{2}{c}{ Cases } & \multicolumn{2}{c}{ Controls } \\
& $\%$ & $\mathbf{N}$ & $\%$ & $\mathbf{N}$ \\
Diabetic, or reported at & & & & \\
least one first or second & & & $30.0 \%$ & 30 \\
degree relative with diabetes & $49.0 \%$ & 49 & $60.0 \%$ & 60 \\
Reported no diabetes & $43.0 \%$ & 43 & $10.0 \%$ & $10^{2}$ \\
Missing, excluded & $8.0 \%$ & $8^{1}$ & $100.0 \%$ & 100 \\
$\quad$ Total & $100.0 \%$ & 100 & &
\end{tabular}

$\mathrm{x}^{2}=7.4,1 \mathrm{df}, \mathrm{P}<.01$

'Seven cases who reported only a diabetic relative who was neither first nor second degree, one adopted case.

${ }^{2}$ Nine controls who reported only a diabetic relative who was neither first nor second degree, one adopted control. 
taken into consideration, with significantly more MS patients (49\%) than controls $(30 \%)$ reporting that they were diabetic or had at least one first or second degree relative with diabetes (Table II). Some of the MS patients and controls mentioned only cousins, nephews/nieces with diabetes, but these were excluded from the above analyses because they were not full blood relatives.

\section{MS Patients with a Family History of Both $M S$ and Diabetes}

Twenty-nine per cent of the MS patients reported a blood relative with MS. The majority of cases reported were verified through interrogating family members who might confirm the information. Cousins, nieces and nephews were included here, since it is more probable that susceptibility to MS was acquired from the MS patients' family than through marriage.

Of those MS patients reporting a relative with MS, $44.8 \%(\mathrm{~N}=13)$ were diabetic or reported a first degree relative with diabetes, and $55.6 \%$ $(\mathrm{N}=16)$ were diabetic or reported either a first or second degree relative with diabetes.

Of the patients who had no relative with $\mathrm{MS}, 25.7 \%(\mathrm{~N}=18)$ were diabetic or reported a first degree relative with diabetes, and $47.1 \%(\mathrm{~N}=33)$ were diabetic or had either a first or second degree relative with diabetes. Thus, there tended to be an increased prevalence of diabetes in families where there was more than one member with MS, although differences between the quoted percentages are not statistically significant at the .05 level.

\section{Limitations of the Findings}

No attempt was made to verify the information on diabetic relatives given by the MS patients or controls. This would have entailed contacting many relatives of both groups. If we had contacted only those identified as having diabetes, we might have been able to estimate overreporting but we would also have had to contact all relatives not listed as diabetic, in order to estimate underreporting. The time and cost to accomplish this were prohibitive.
Nevertheless we consider it unlikely that either MS patients or controls would report incorrectly, or be unaware of, diabetes in a parent, sibling or child. In light of the hereditary factor, we also feel that most of the MS patients and controls would be alert to diabetes among their grandparents, or aunts and uncles. Both the MS patients and controls were able to provide information on age at diagnosis and treatment regimen for more than $75 \%$ of the relatives named as diabetic. The ability to provide these details suggests that neither group was reporting illness where it did not exist. Finally, the MS patients reported that $3.7 \%$ of their relatives at risk were diabetic, and the controls reported $2.5 \%$; both figures are within the prevalence range of 2$4 \%$ estimated for the general population (Forbath, 1981).

Differences in the age, sex, and socio-economic status of the MS patients' and controls' family members might affect their rates of diabetes. We do not have complete information on the socio-economic status of the families of patients and controls but the patients and controls did not differ in terms of occupational category. There was a tendency for the patients' fathers to have been farmers, while the controls' fathers clustered in the white collar category. However, diabetes is considered to be more prevalent among the higher socio-economic classes (Steinke and Thorn, 1974). There was no significant difference between the MS patients and controls according to the percentages of male or female relatives they reported. We had no specific information on the ages of their relatives but, since the patients and controls were age-matched, we might infer that the age distribution of their relatives would be similar.

No bias was introduced by the means in which controls were selected to supplement those who were recommended by the MS patients. Of the 34 woman's club controls used, $35.3 \%$ $(\mathrm{N}=12)$ were diabetic or reported a family member with diabetes; of the 17 controls recommended by the two other organizations, $23.5 \% \quad(\mathrm{~N}=4)$ reported diabetes; of the 30 staffrecommended controls, $26.7 \%(\mathrm{~N}=8)$ reported diabetes; for the 19 patientrecommended controls the figure was $36.8 \%(\mathrm{~N}=7)$. There was no significant difference between any of these percentages.

\section{DISCUSSION \\ Comparison with the Previous Study}

This study confirms the relationship between multiple sclerosis and diabetes mellitus observed in our previous report (Warren and Warren, 1981). In both studies, significantly more MS patients than controls were diabetic or reported at least one first or second degree relative with diabetes. This time, the difference between MS patients and controls was greater; $19 \%$ more of the MS patients reported a family history of diabetes than the controls. In the previous study, only $13 \%$ more of the MS patients reported diabetes than the controls.

In contrast to the previous study, this one found no statistical association between familial multiple sclerosis and diabetes mellitus, though there was an increased prevalence of diabetes in families where there was more than one member with MS.

Although both studies indicate a possible relationship between multiple sclerosis and diabetes mellitus, support for such a relationship is expressed somewhat differently. In the previous study, MS patients and controls were not specifically asked about the prevalence of diabetes in their families; the relationship was noted fortuitously. In this study, both groups were asked about diabetes in detail, which should have improved the reporting. Thus one might have expected the MS patients and controls to differ more if a relationship between MS and diabetes does in fact exist. If diabetes is associated with other neurological and rheumatological diseases for which some of the original controls may have been hospitalized, the use of healthy controls rather than hospital patients may have had an effect.

The association between familial MS and a family history of diabetes mellitus may have disappeared in this study, as a result of a different pattern in the reporting of diabetes by female MS patients. The previous study in- 
cluded 70 female and 30 male MS patients. A smaller proportion of the women $(32.9 \%, \quad \mathrm{~N}=23)$ reported a relative with diabetes than the men (46.7\%, N=14). However, among the 12 women reporting another MS relative, $75 \%(\mathrm{~N}=9)$ reported a diabetic relative; while, among the six men reporting an $\mathrm{MS}$ relative, only $50 \%(\mathrm{~N}=3)$ reported diabetes in their families.

This study included 74 female and 26 male MS patients. This time $56.8 \%$ $(\mathrm{N}=42)$ of the female MS patients and $53.9 \%(\mathrm{~N}=14)$ of the men reported a relative with diabetes, approximately equal proportions. Similarly, among the subgroup of MS patients with another MS relative, approximately equal proportions of women $(56.5 \%$, $\mathrm{N}=13 / 23)$ and men $(50 \%, N=3 / 6)$ reported a relative with diabetes.

The reason for the discrepancy in the female reporting is not clear. Since the mean age of the females with another MS relative was almost identical in the two studies (38.4 and 39.3 respectively), age is probably not a contributing factor. The prevalence of diabetes in the general population increases with age (Steinke and Thorn, 1974), but the first group's relatives should not have had longer than the second group's relatives to develop diabetes. Some differences in the sex distribution of the womens' relatives at risk in the two studies may account for the difference, since women past a certain age have a greater risk of developing diabetes than men (Steinke and Thorn, 1974).

\section{Additional Information Provided}

Several points were raised when the original study was published. The most frequent criticism was that no distinction was made between juvenile-onset and adult-onset diabetes. In this study, we asked participants to state both the age at onset in their diabetic relatives and the treatment regimen being followed.

Only one MS patient, and none of the controls, listed a first or second degree relative with juvenile-onset diabetes. Treatment regimens were tabulated for the MS patients and controls, and for first and second degree relatives. None of the MS patients, and only one control, were taking insulin. Of the MS patients' relatives who were diabetic, $28.8 \%(\mathrm{~N}=19$ out of 66 for whom information was available) were taking insulin, while the remainder were being treated by diet alone, or some combination of diet and oral medication. Of the controls' first and second degree diabetic relatives, $20.9 \%(\mathrm{~N}=9$ out of 43) were taking insulin.

Juvenile-onset or insulin-dependent diabetes mellitus (IDDM) is strongly associated with the DR3 haplotype, and there is evidence that DR3 is also increased in MS patients (Ebers, 1980). Therefore it would not be surprising to find an increased frequency of IDDM among MS patients. However our studies indicate that the relationship is between multiple sclerosis and adultonset or non-insulin-dependent diabetes, since the difference between our MS patients and controls, in terms of the proportions of their diabetic relatives being treated by insulin, was less than ten per cent.

\section{Implications of the Findings}

In our previous report (Warren and Warren, 1981), we suggested that an association between MS and diabetes mellitus might indicate that some metabolic disorder is involved in the development of MS. For example, Alter (1977) and Dick (1976) have hypothesized that dietary excesses of certain fats may cause errors in the formation of myelin, rendering it unstable or susceptible to attack by some causal agent such as a virus. Abnormalities in fat metabolism have been observed in diabetic patients with relatively mild insulin deficiency (Sherwin and Felig, 1978).

Other authors (Craelius, 1978; Goldberg, 1974) have presented evidence that adequate supplies of calcium are necessary for proper myelin development. However Raskin et al (1978) have associated uncontrolled diabetes with an excessive urinary loss of calcium in adult diabetics; and Hoskins et al (1979) found a significant decrease in active uptake of calcium by the kidney in streptozotocin-diabetic rats, prior to evidence of nephropathy.

It has also been hypothesized that a disorder in myelin synthesis underlies the neuropathy in diabetes. Thomas (1965) has demonstrated loss of myelin corresponding to segments of nerve underlying individual Schwann cells in single isolated nerve fibers from diabetic patients. This supports the idea that diabetic neuropathy reflects a disorder of the Schwann cell, which expresses itself by defective myelin formation. Spritz (1978) has reviewed the evidence for and against this theory, including research which indicates that hormones known to be present in diabetes influence metabolic reactions in the Schwann cell related to the synthesis of myelin.

Roberts (1966) observed decreased glucose tolerance in 12 MS patients, and hypothesized that multiple sclerosis is a reaction by the nervous system to metabolic injury resulting from the combined effects of glucopenia and edema, enhanced by a chronically hyperinsulinized state. He has suggested that the ingress of water into myelin disrupts its maximal intermolecular cohesion and functional integrity.

Sorensen et al (1980) recently reported decreased levels of somatostatin, a polypeptide secreted by the hypothalmus which inhibits the release of insulin in MS patients suffering acute exacerbations.

Whether any of these observations have implications for a link between diabetes mellitus and multiple sclerosis is speculative. This study does provide further evidence that such a relationship does exist.

\section{ACKNOWLEDGEMENTS}

This research was supported in part by: the Multiple Sclerosis Society of Canada; the Medical Services Research Foundation Incorporated of Alberta; the Special Services and Research Committee of the University of Alberta Hospital; the Association of Canadian Travellers (Alberta Division); Friends of the University of Alberta MS Research Clinic; and Health and Welfare Canada. We gratefully acknowledge the assistance of our interviewers, Mrs. Margot Paterson and Mrs. Isobel Patterson, and typist, Connie Kovalenko. We would also like to thank the groups whose members participated as controls (the Junior League, Royal Canadian Legion, and Sun Life Co. of Canada and those from other sources) and the MS patients themselves. 


\section{REFERENCES}

ACHESON, E.D. (1972) The epidemiology of multiple sclerosis. In Multiple Sclerosis: A Reappraisal, McAlpine, D., Lumsden, C.E. and Acheson, E.D. (Eds.), Churchill Livingston, London.

ALTER, M. (1977) Clues to the cause based upon the epidemiology of MS. In MS: A Critical Conspectus, Field, E.J. (Ed.) University Park Press, Baltimore.

CRAELIUS, W., NEWBY, N. and THOMAS, F.C. (1978) Central myelination in vitro: effect of reduced calcium and magnesium. Neurological Absts.

DICK, G. (1976) The etiology of multiple sclerosis. Proc. Roy. Soc. Med. 69: 611-15.

EBERS, G. MS Clinic, University of Western Ontario, London, personal communication, 1980.

EHRENTHEIL, O., SCHULMAN, $M$. and ALEXANDER, L. (1952) Role of food allergy in multiple sclerosis. Neurology, 2: 412-27.

FORBATH, N. (1981) Diabetes and its complications. Med. Clin. N.A., 12: 1300-7.

FROVIG, A., PRESTHUS, J. and SPONHEIM, N. (1967) The significance of allergy in the etiology and pathogenesis of multiple sclerosis. Acta Psych. (Scand.), 43: 215-25.

GOLDBERG, P. (1974) Multiple sclerosis: vitamin $D$ and calcium as environmental determinants of prevention. Parts I and II. Inter. J. Envir. Stud., 6: 19-27, 121-29.

HOSKINS, B., FEIBELMAN, R., LOURY, A. et al. (1979) Effectiveness of insulin therapy on altered renal calcium transport in diabetic rats. Diabetes, 28: 1088-94.

MCALPINE, D. and COMPSTON, M.D. (1952) Some aspects of the history of disseminated sclerosis. Quar. Jour. Med., 21: 135-67.

RASKIN, P., STEVENSON, M., BARILLA, D. et al. (1978) The hypercalcuria of diabetes mellitus: its amelioration with insulin. Presented at the 38th Annual Meeting of the American Diabetes Association, Boston.

ROBERTS, H. (1966) On the etiology, rational treatment and prevention of multiple sclerosis. Southern Med. J., 59: 940-50.

SHERWIN, R. and FELIG, P. (1978) Pathophysiology of diabetes mellitus. In Symposium on Diabetes Mellitus. Med. Clin. N.A., Podolsky, S. (Ed.), W.B. Saunders, Co., Philadelphia.
SIBLEY, W.A., BAMFORD, D. and LAQUNA, F. (1978) Anamnestic studies in multiple sclerosis: a relationship between familial multiple sclerosis and neoplasia. Neurology, 28: 125-29.

SORENSEN, K., CHRISTENSEN, S., DU. PONT, E., HANSEN, A., PEDERSON, E. and ORSKOV, H. (1980) Low somatostatin content in cerebrospinal fluid in MS: An indicator of disease activity? Acta Neuro. Scand. 61: 186-191.

SPRITZ, N. (1978) Nerve disease in diabetes mellitus. In Symposium on Diabetes Mellitus. Med. Clin. N.A., Podolsky, S. (Ed.), W.B. Saunders, Co., Philadelphia.

STEINKE, J. and THORN, G. (1974) Diabetes mellitus. In Harrison's Principles of Internal Medicine (7th Edition), Wintrobe, $M$. et al. (Eds.), McGraw-Hill, New York, pp. 53250.

THOMAS, P.K. and LASCELLES, R.G. (1965) Schwann-cell abnormalities in diabetic neuropathy. Lancet, 1: 428-31.

WARREN, S.A. and WARREN, K.G. (1981) Multiple sclerosis and associated diseases: a relationship to diabetes mellitus. Can. J. Neur. Sci. 8: 35-39.

WATKINS, S. and ESPIR, M. (1969) Migraine and multiple sclerosis. J. Neuro. Neurosci. Psych. 32: 35-37. 